University of Warwick institutional repository: http://go.warwick.ac.uk/wrap This paper is made available online in accordance with publisher policies. Please scroll down to view the document itself. Please refer to the repository record for this item and our policy information available from the repository home page for further information.

To see the final version of this paper please visit the publisher's website. Access to the published version may require a subscription.

Author(s): Andrew J. Oswald and Nattavudh Powdthavee Article Title: Does happiness adapt? A longitudinal study of disability with implications for economists and judges

Year of publication: 2008

Link to published version:

http://dx.doi.org/10.1016/j.jpubeco.2008.01.002

Publisher statement: None 


\title{
Does Happiness Adapt? A Longitudinal Study of Disability with Implications for Economists and Judges
}

\author{
Andrew J. Oswald \\ University of Warwick \\ Email: andrew.oswald@warwick.ac.uk \\ Nattavudh Powdthavee \\ University of London \\ Email: n.powdthavee@ioe.ac.uk
}

December 23, 2007

Forthcoming in the Journal of Public Economics

\begin{abstract}
$\underline{\text { Abstract }}$
This paper is an empirical study of partial hedonic adaptation. It provides longitudinal evidence that people who become disabled go on to exhibit considerable recovery in mental well-being. In fixed-effects equations we estimate the degree of hedonic adaptation at -- depending on the severity of the disability -- approximately $30 \%$ to $50 \%$. Our calculations should be viewed as illustrative; more research, on other data sets, is needed. Nevertheless, we discuss potential implications of our results for economists and the courts.
\end{abstract}

Keywords: Disability; adaptation; happiness; legal compensation; well-being; GHQ

JEL codes: D1, I3, I31, K0

Corresponding author: andrew.oswald@warwick.ac.uk.

Address: Department of Economics, University of Warwick, Coventry CV4 7AL.

Telephone: (+44) 02476523510

Acknowledgements: For many helpful comments, we thank the editor Emmanuel Saez and two referees. We are grateful also to participants in seminars at Amsterdam, Birmingham, Cambridge, Cardiff, Harvard, LSE, Sheffield, and Warwick, and to Ian Walker, Andrew Clark, Paul Dolan, Dick Easterlin, Daniel Gilbert, Amanda Goodall, Carol Graham, Mark Harrison, Emanuel Kohlscheen, Erzo Luttmer, Jennifer Reinganum, Jennifer Smith, Mark Stewart, Alois Stutzer, and Bernard Van Praag. The Economic and Social Research Council (ESRC) provided research support. The usual disclaimer applies. The British Household Panel Survey data were made available through the UK Data Archive. The data were originally collected by the ESRC Research Centre on Micro-social Change at the University of Essex, now incorporated within the Institute for Social and Economic Research. Neither the original collectors of the data nor the Archive bear any responsibility for the analyses or interpretations presented here. A longer working-paper version of this paper is available in the form of Oswald and Powdthavee (2005). 


\section{Does Happiness Adapt? A Longitudinal Study of Disability with Implications for Economists and Judges}

\section{$\underline{1 . \text { Introduction }}$}

Many writings in the psychology literature argue that utility recovers after a bad life shock. This is the idea that human beings bounce back from adversity ${ }^{1}$. By contrast, the economics literature assumes a given utility function $\mathrm{u}(\mathrm{x})$ in which there is generically no habituation or adaptation ${ }^{2}$. Such an apparent divide between two social-science disciplines is scientifically unattractive.

Our paper focuses on a particular negative event, that of the onset of disability, and attempts empirically to explores this issue. We present econometric evidence consistent with the existence of hedonic adaptation -- to use the term of Frederick and Loewenstein 1999 -- to disability. In many cases, the degree of adaptation appears to be large (although partial, i.e. not routinely 100\%). Our results suggest that economists may need to revise their standard conceptual apparatus.

More specifically, this paper documents evidence for partial hedonic adaptation:

(i) in cases of moderate disability in British micro data, the extent of hedonic adaptation is estimated at approximately $50 \%$

(ii) adaptation to severe disability is of the order of $30 \%$.

In an appendix, we replicate the tenor of these findings on a German micro data set. There we find adaptation of a similar size.

\section{Background}

\footnotetext{
1 One of the famous papers is Brickman et al (1978). It is often claimed that this shows that lottery winners are no happier than non-winners and paraplegics are as happy as able-bodied individuals. In fact, the paper, which uses tiny cross-sections, does not say either of these things. Brickman et al report data in which disabled people do have lower life-satisfaction scores than the able-bodied, and this difference, when compared to a control group, is statistically significant at conventional levels. Moreover, lottery winners do have higher life-satisfaction scores than the controls, although the null hypothesis of no difference is not rejected at the $5 \%$ level.

2 There is work on habit-formation, but that is not exactly the same as hedonic adaptation.
} 
There is little economic theory in this area. Rayo and Becker (2007), Wilson and Gilbert (2005) and Graham and Oswald (2005) sketch theories of happiness adaptation. The first, by economists, likens hedonic adaptation to the ability of the human eye to adjust quickly -- for sound reasons of self-preservation -- to changes in the amount of light. Rayo and Becker set out a model of how Nature might optimally have designed human beings' emotional responses to behave a similar way. The second paper, by two psychologists, instead views humans as learning to change what they attend to and how they react. Wilson and Gilbert suggest that hedonic adaptation is not reducible to the type of adaptation found in the sensory systems. The authors argue that affective habituation stems instead from the human need to explain and make sense of stimuli. They advocate what they describe as an AREA model: attend; react; explain; adapt. In the third paper, Graham and Oswald show how hedonic adaptation emerges from a model of evolution in which Nature 'rationally' uses happiness as a device to make agents value their lives efficiently.

Econometric evidence is also scarce. One of the few empirical economists to study the phenomenon of utility adaptation has been Easterlin (2001, 2003, 2005). He argues that adaptation exists but is generally incomplete, namely, that people do not merely automatically return to a baseline level of happiness ${ }^{3}$. Clark and Oswald (1994) find cross-section evidence consistent with the idea of partial adaptation by the long-term unemployed. Riis et al (2005), using an ecological momentary-assessment measure of mood, find little evidence that hemodialysis patients are any less happy than healthy people. The authors suggest that patients in the sample have adapted to their condition. Other investigators, such as Clark (1999), Clark et al (2007), Stutzer (2004) Layard (2005) and Di Tella, Haisken and MacCulloch (2005), have begun to consider the economic implications of whether and how people adapt. Kahneman and

\footnotetext{
${ }^{3}$ So-called set point theory is the psychologists' term for the idea that people adapt fully to everything. Another term for habituation in the literature is affective adaptation, which is the process, to quote Wilson and Gilbert's (2005) definition, whereby affective responses weaken after one or more exposures to a stimulus. Valuable discussions, with examples, are in Lucas et al (2003) and Lyubomirsky et al 2005. Earlier evidence is discussed in Argyle (1989), Diener et al (1999) and Groot and Van den Brink (2000). Affective forecasting is known to be imperfect (Gilbert et al 1998, 2002; Ubel et al 2005). Senik (2004) and Ferrer-i-Carbonell (2005) document the importance of comparisons more broadly. Groot (2000) discusses adaptation biases and so-called QUALYs, and Burchardt (2005) examines panel data on financial satisfaction. Menzel et al (2002) study disability but do not have longitudinal data on well-being. Linley and Joseph (2004) is an interesting review of a related literature on the border of medicine. An axiomatic conceptual model is described in Gilboa and Schmeidler (2001).
} 
Sugden (2005) argue that it is important to allow in policy-making for adaptation in experienced utility. Di Tella, MacCulloch and Oswald (2001, 2003), by estimating dynamic equations, find evidence that the national well-being consequences of shocks to gross domestic product seem eventually to wear off. But currently the economics literature is small 4 and the extent of any hedonic adaptation is imperfectly understood.

\section{A Framework}

To fix ideas, assume that, in a first stage, a person has to choose some action, e, to maximize his or her expected utility. The variable e might be viewed as, for example, the amount of investment in education. There is some measure of the person's health, $\mathrm{h}$, that lies in the unit interval. The world is uncertain in the sense that there are random shocks ${ }^{5}$ to health with density function $\mathrm{f}(\mathrm{h})$. The action is taken before the state of the world is revealed, and helps to determine the individual's income, $y$, through some increasing function $y(e)$. The cost of action is given by an increasing function c(e).

We need a way to conceptualize disability. To do this, assume that there is some cutoff level of health below which the person is unable to work: this happens when $h \leq \hat{h}$. If disabled, the individual gets non-labor income $\mathrm{z}$, which is some external (possibly government) support. The action, e, may itself affect the range of outcomes, that is, the outcome in the possible state of nature. Education can also determine the level of physical disability, for example, at which work becomes impossible. More highly educated individuals may more easily be able to be physically disabled and hold a job.

Let expected utility be

\footnotetext{
4 In principle, the adaptation literature is also related to work on broader conceptions of preferences such as Frey and Meier (2004).

5 New work by Easterlin et al (2006) studies more general health changes than the disability shock we later discuss.
} 


$$
E V=\int_{0}^{\hat{h}(e)} u(z, h) f(h) d h+\int_{\hat{h}(e)}^{1} u(y(e), h) f(h) d h-c(e)
$$

where the first term represents the level of utility in the disabled state and the second term the utility level in the able-bodied state. Define education level $\mathrm{e}^{*}$ as the argmax of equation (1). It is characterized at an interior optimum by

$$
\frac{\partial E V}{\partial e}=\hat{h}^{\prime}(e)[u(z, h)-u(y, h)] f(\hat{h})+\int_{\hat{h}}^{1} \frac{\partial u}{\partial y} y^{\prime}(e) f(h) d h-c^{\prime}(e)=0 .
$$

After the state of nature, $\mathrm{h}$, has arrived, the individual in the second stage is either able-bodied or not, and utility ex post is then one of:

$$
\begin{array}{ll}
V=u(z, h)-k & \text { disabled } \\
V=u(y, h)-k & \text { healthy }
\end{array}
$$

where $\mathrm{k}$ is a constant given by the derivative of $\mathrm{c}(\mathrm{e})$ evaluated at $\mathrm{e}=\mathrm{e}^{*}$.

For pedagogical reasons, take the case of additive separability. Assume an ablebodied individual's utility function is

$$
V=v(y)+h
$$

where $\mathrm{v}($.$) is increasing and concave in the person's income, \mathrm{y}$, and $\mathrm{h}$ is overall health. After a disabling shock at time T, which makes work impossible, assume that wellbeing drops to

$$
V=v(z)+h-D
$$

where the disability variable $\mathrm{D}$ is a simple shift parameter, and $\mathrm{z}$ is again some external (government benefit) financial support. Assume y strictly greater than z.

In the case of adaptation to disability, define a habituation function $\mathrm{D}=\mathrm{D}(\mathrm{t}-\mathrm{T})$, where $t$ is the current time period, $\mathrm{T}$ was the original date of disability, and the first derivative of the function $\mathrm{D}($.$) is negative. { }^{6}$ What are the implications? Consider a case in which legal compensation is being decided. If a judge's aim is, ex post, to redress the individual's fortunes and restore his or her original utility level, the optimal compensation is a monetary payment $c^{*}$ that provides equality of utility levels

\footnotetext{
6 The earlier formulation assumes, perhaps plausibly given the affective-forecasting literature, that individuals do not realize they will adapt hedonically. But the structure of the maximization could be altered to allow for more knowledge.
} 
in the two states. At the general level, therefore, there exists an implicit function tying together income, compensation, external support, time, and time of the disability shock:

$J(y, c, z, t, T)=0$.

Solving $\mathrm{J}=0$ more explicitly under the assumptions above, movements in compensation $\mathrm{c}^{*}$ are governed locally by the equation

$0=v^{\prime}(y) d y-v^{\prime}\left(c^{*}+z\right) d c^{*}-v^{\prime}\left(c^{*}+z\right) d z+D^{\prime}(t-T) d t$

so the key signs of the partial derivatives of the optimal payment function with respect to time-since-disability, t, income, $\mathrm{y}$, and outside support, $\mathrm{z}$, are then respectively negative, positive, and exactly minus unity:

$$
\begin{aligned}
& \frac{\partial c^{*}}{\partial t} \leq 0 \\
& \frac{\partial c^{*}}{\partial y} \geq 0 \\
& \frac{\partial c^{*}}{\partial z}=-1 .
\end{aligned}
$$

As time $t$ lengthens from the onset of disability, the compensation level $c^{*}$ falls. This is because psychological adaptation gradually reduces the unhappiness caused by the disability. Second, the higher is the person's pre-disability income, the greater is c*. High-wage workers should be compensated more generously for disability. Third, a larger amount of external support $\mathrm{z}$ leads to a reduction in compensation $\mathrm{c}^{*}$ by an exactly offsetting amount. Court settlements can be less generous where other funds become open to disabled individuals 7 .

Although these functional forms are deliberately elementary, the principles go through with non-separable well-being equations and more complex forms of income pre- and post-disability. Time-varying compensation will be a typical, not special, outcome in a world with hedonic adaptation (although judges can formally make an award as an appropriate lump-sum present value). These ideas can be generalized.

\footnotetext{
7 A reasonable question to ask is why insurance is not included in the analytical framework (as in Gruber's (2000) work on the effects upon labor supply). We deliberately leave this to one side both for later data reasons and one conceptual reason: except in a world with full insurance markets, it does not alter the underlying principle that judges will need to prescribe, or at least implicitly bear in mind the case for, time-contingent compensation.
} 
As a referee has pointed out, we could allow for a set of determinant-specific habituation coefficients in equation (8).

\section{$\underline{\text { 4. Implementing a Test }}$}

Nevertheless, as an empirical matter, do people bounce back from a bad life event? A test has to have a number of special features:

(i) individuals in the sample must be followed over a reasonably long period, so that information on them is available before a bad life event;

(ii) the life event should have an exogenous element;

(iii) there needs to be a control group who do not suffer the event;

(iv) the sample should be representative of the adult population;

(v) a set of other variables, particularly on income, has to be available in the data set, so that confounding influences can be differenced out.

No study of this type has apparently been published in the economics literature (some, including Clark et al 2007 and Riis et al 2005, and the seminal panel-data paper on unemployment by Winkelmann and Winkelmann 1998, satisfy a number of these requirements). However, Ferrer-i-Carbonell and Van Praag (2002) and Groot et al (2004) explore the negative well-being effect of various diseases.

One example of a major life event is disability. Although tragic for the individual, for scientific investigators this phenomenon has valuable features. First, it might be viewed -- like the heart conditions studied by Wu (2001) -- as closer to an exogenous event than many influences recorded in micro data sets ${ }^{8}$. Hence it contrasts with the (interesting) phenomena of, say, income changes and divorce, which have been studied longitudinally. Second, going back at least to Brickman et al (1978), there has been inconclusive psychological research on whether people's well-being recovers fully from disability ${ }^{9}$. Using a large cross-section, Ville and Lavaud (2001) argue that more severely impaired people have lower well-being; but time-since-the-

\footnotetext{
${ }^{8}$ As a referee has pointed out, strict exogeneity is not needed for the analysis to be of value.

${ }^{9}$ Current empirical evidence indicates that different life events may have different adaptation patterns. For example, Clark et al (2007) show that while people adapt to divorce they do not seem to adapt to unemployment (the latter is also suggested by the findings of Clark and Oswald, 1994).
} 
disability is not a statistically significant predictor. In a small cross-section, Chase, Cornille and English (2000) also find that the extent of disability is negatively correlated with life satisfaction. Yet, as explained earlier, Riis et al (2005) do conclude in favour of extreme adaptation to hemodialysis. Third, the courts routinely consider damage-claims for disability, but currently appear to have no rigorous way to assess mental damages or pain-and-suffering, so the issue is of practical significance.

Particular mention should be made of recent work -- done independently of our own -by the psychologist Richard E. Lucas, as especially in Lucas (2007). In his article, the author concludes that there is essentially no adaptation to disability. Lucas's work is in opposition to the tradition in psychology journals. His data sets are the same as those we use later, although the statistical technique is not classical regression analysis. Nevertheless, our conclusions are different from his. ${ }^{10}$ The explanation appears to be that Lucas (2007) relies on multi-level methods that are technically closer to what economists would term random-effects equations. Particularly when we use fixed-effects equations, evidence for adaptation emerges.

Our main data set comes from waves 7 to 14 of the British Household Panel Survey (BHPS). This is a nationally representative of British households, which contains over 10,000 adult individuals, conducted between September and Christmas of each year from 1991 (see Taylor et al., 2002). Respondents are interviewed in successive waves; households who move to a new residence are interviewed at their new location; if an individual splits off from the original household, the adult members of their new household are also interviewed. Children are interviewed once they reach 11 years old. The sample has remained representative of the British population since the early 1990s. The entire sample of the unbalanced panel contains 22,957 individuals -- 5,309 of whom stayed in all waves from wave 7 onwards. A table of descriptive statistics is provided in the appendix.

\footnotetext{
10 We saw Richard Lucas's work when it was published in autumn 2007. The author does not discuss our findings. Our paper appeared on the web in 2005 and was sent to Lucas in 2006. Given the technical differences in methodology, and the different presentation styles in psychology and economics journals, we cannot be certain why we find much more adaptation than does Lucas. It seems likely that future research will have to return to this issue.
} 
For 1996 to 2004, psychological well-being scores on each person are available. Respondents also provide information on physical disability, which is available from 1991 onwards. We focus on quite serious levels of impairment: people who say that they are sufficiently disabled that they are unable to work. In the entire data set of seven years, there are approximately 65,000 person-year observations. Within this, there are approximately 2500 person-year observations of disability.

The paper draws on two survey questions in the BHPS. These are: (i) What describes your current situation ... long term sick or disabled? (ii) Does your health in any way limit your daily activities compared to most people your age?

One empirical category that we employ is 'disabled but able to do day-to-day activities including housework, climbing stairs, dressing oneself, and walking for at least 10 minutes'. We denote this Moderately Disabled. The other, even more fundamentally impaired, category is 'disabled and unable to do at least one of the above day-to-day activities.' We term this group the Severely Disabled. In the unbalanced panel, there are 675 observations (i.e. person-years) in the first category. There are 3,442 observations in the second category. The figures reduce to 292 observations in the first category, and 1,723 observations in the second category in the balanced panel. It might seem surprising that the Severely Disabled outnumber the less seriously disabled, but that is because all these individuals are sufficiently incapacitated that they cannot work, and this is more commonly accompanied by some extreme physical handicap.

\section{$\underline{\text { 5. Longitudinal Patterns }}$}

When trying to understand the consequences of an event like disability, it is necessary to go beyond the pecuniary. Mental distress itself must somehow be empirically captured. Our analysis uses reported life-satisfaction scores as psychological wellbeing, or proxy-utility, measures.

In the British data, life satisfaction levels scores can run from 1 to 7 . One way to think about people's answers is as being true utility levels measured with some 
reporting error ${ }^{11}$. Disabled people show up as markedly less happy than the ablebodied. On a 1 to 7 scale, the mean raw life-satisfaction score of Not Disabled individuals in our data set is 5.28. It has a standard deviation of 1.27. The 315 people who are disabled but able to do day-to-day activities are less happy than average. Their mean life-satisfaction score is 4.69, with a standard deviation of 1.67. The 2204 severely disabled individuals, who cannot do those activities, are worse off still. Their mean well-being score is 4.05 , with a standard deviation of 1.78 .

As would be expected, there are some people (129 to be exact) who report disability in every year of the panel. These observations are not the most helpful scientifically: they provide no information about transitions into disability. Nevertheless, the gap in reported life satisfaction scores between these 'always disabled' individuals and the 'always able-bodied' can be calculated. The 13,776 people who never report disability have a mean well-being score of approximately 5.3 on a 1 to 7 scale. Those 129 who are constantly disabled have a mean score of approximately 4.3. Hence the raw difference associated with disability is approximately 1 life-satisfaction point. Such numbers, however, make no allowance for emotional habituation or, more simply, the idea that the intensity of feelings may wear off. How can such adaptation be studied in a regression framework? The paper later does this in the following way. It defines a variable for the amount of time people have spent disabled. That fraction of time is then included in well-being equations to see if, in the current period, ceteris paribus, past experience softens the psychological blow of current disability.

Figure 1 is a longitudinal plot of the mental well-being of people who become disabled. Here the disability category includes both kinds in the data set ('able' and 'unable' to do day-to-day things). Time $\mathrm{T}$ is the year of entry into disability. In effect, this plot averages across those who are newly disabled in each of the different calendar years within the data set.

In Figure 1, there are 61 people on whom there are at least five consecutive years of well-being data. Figure 1 reveals that life-satisfaction is approximately 4.8 in both

11 Oswald (1997) and Frey and Stutzer (2002) summarize ways in which reported well-being numbers' validity has been checked. Blanchflower and Oswald (2004) show that, where data on both are available, happiness equations and life-satisfaction equations have almost identical structures. 
year T-2 and year T-1. It then falls abruptly. It is approximately 3.7 in the actual year that the person reports being disabled (this drop is thus similar in size to that of the raw cross-section difference). After that, life-satisfaction in Table 1 starts to rise back up. It reaches 4.1 in year $\mathrm{T}+2$. Hence, there is some evidence consistent with a bounce-back in mental well-being. Nevertheless, there is much inherent variation in well-being scores and the points in Figure 1 have large standard errors attached.

The pre-disability level of life satisfaction in Figure 1 is lower than for the mean in the British population. If disability struck randomly, and in a way that is independent of other personal characteristics, this would not be expected. Whilst this is likely to be inescapable in real-world data, it is a reminder that disability is more common among those with disadvantageous life characteristics, and that it is sometimes preceded by a slow worsening of health or functioning. It might be thought that a low level of measured well-being prior to entering disability at time $\mathrm{T}$ compromises disability's claim to be seen as an appropriate variable. But consider a person who gradually becomes ill through the years -- eventually recording themselves as disabled in time period T. The person's move is still a predetermined variable. Nevertheless, the existence of such individuals in the data set will pull down the parameter estimate on disability in a well-being equation.

Finally, an additional check on the issue of exogeneity was done (as suggested by a referee). The sample size is necessarily tiny, and standard errors are large, but Figure 2 provides the equivalent plot for the case of lasting disability through an accident. Here there is a larger fall in well-being, of nearly a full 2 points, together with a recovery, by year $\mathrm{T}+2$, of slightly more than half the initial life-satisfaction drop.

\section{$\underline{\text { 6. Econometric Results }}$}

Table 1 moves to econometric evidence. The dependent variable is life satisfaction measured 12 cardinally (on the 1 to 7 scale). Standard controls are entered into the equation. Age is entered as a second-order polynomial; it has the literature's

12 All the paper's results can be replicated with ordered estimators. But, as in the paper by Luttmer (2005), as a pedagogical device and for ease of reading we here use cardinal methods. 
conventional U-shape, minimizing in the late 30s. Dummy variables are included for people's qualifications. Educational level in many circumstances will be an approximately predetermined variable (though not for those disabled in childhood). The logarithm of income is entered as a regressor. Demographic and personal variables are also included.

We experimented with long lags, up to t-6. However, here we report only estimates of the effect of current, and up to the past three years of, disability upon life satisfaction (see Clark et al, 2001, for a discussion of another model used to test for habituation effects).

The idea is that if there is hedonic adaptation to disability then we should observe that disability hurts but that it does so to a smaller degree the longer the individual has been disabled. The paper creates a variable "Ratio of time spent being disabled from t-3 to t-1". This takes a value between zero and unity. A person who has been disabled for one previous year in the last three years, for example, will have the value 1/3 for his or her past disability from t-3 to $t-1$.

More fully:

"Ratio of time spent being disabled from $t-3$ to $t-1$ "

$=0$ if no previous years of disability

$=1 / 3$ if one previous year of disability

$=2 / 3$ if two previous years of disability

$=1$ if all three previous years were of disability.

As part of the empirical strategy, these variables are entered separately and interacted with measures of current disability. The main equation that we estimate is:

$$
L S_{i t}=\alpha_{0}+\alpha_{1} D_{i t}+\alpha_{2} \text { PASTD }_{i t}+\alpha_{3}\left(D_{i t} \times \operatorname{PASTD}_{i t}\right)+X_{i t}^{\prime} \gamma+\varepsilon_{i t},
$$


where $L S_{i t}$ is self-rated life satisfaction at $t, D_{i t}$ is a dummy variable with value of 1 if the respondent is disabled at $t$ and 0 otherwise, $P A S T D_{i t}$ is the ratio of past disability between $t-j$ and $t-1$ measured as a percentage of total time spent being disabled, $X$ is a vector of personal and household characteristics affecting life satisfaction, and $\varepsilon_{i t}$ is the error term. Our main results are based on specification that focuses on threeyear past disability $(j=3)$. The estimation of (12) allows a test of the following hypotheses:

(i) the currently disabled report significantly lower life satisfaction than those who are not disabled;

(ii) past disability reduces the current life satisfaction of those who have since recovered from disability -- that is, past disability scars someone, and there is not complete adaptation even for those who recover from disablement;

(iii) the effect of current disability is smaller for those who have been disabled longer or more often in the past, consistent with a habituation effect.

Hence, the hypotheses imply that $\alpha_{1}<0, \alpha_{2}<0$, and $\alpha_{3}>0$. Assuming cardinality in the life satisfaction scale, we estimate equation (12) using GLS with random effects (RE) and individual fixed effects (FE) models.

The coefficient Disabled, in the first column of Table 1, is -0.880 . This implies that, ceteris paribus, the disabled report almost one life-satisfaction point less than other people. The standard error on the coefficient is 0.041 , so that at conventional confidence levels the null of zero is rejected.

The remainder of the disability variables in the first column of Table 1 are for the length of time a person has been disabled. This is to capture the degree of adaptation, if any.

In the first column of Table 1, the ratio of time spent disabled between t- 3 and $\mathrm{t}-1$ has a coefficient of -0.651 . An interaction term for Disabled *Ratio of past disability has a coefficient of 0.525 . These variables and their coefficients make it possible to read off the extent of adaptation. Consider, as a benchmark, a person who is disabled for 
all three of the preceding years. Their accumulated ratio of time spent being disabled from t-3 to t-1 is then 1 . Hence, other factors held constant, the effect on life satisfaction is -0.651 points. However, if they are disabled in time there is an offsetting factor. The net effect of these is $(-0.651+0.535)=-0.116$. We cannot quite reject the null of zero on this net difference. In Table 1's column 2, a different random-effects specification is estimated. Here the disabled variables are divided into each of the two categories of seriousness. Some people (the Moderately Disabled) are able to do day-to-day-activities. The dummy variable coefficient in this case is 0.627. Some are disabled and unable to do day-to-day activities (these are the Severely Disabled). The coefficient on the dummy is -0.959 . As would be expected, more serious disability is thus associated with lower reported well-being. From the second column of Table 1 it is possible to examine adaptation to moderate and severe disability. Consider someone who has been disabled for all of the previous three years. Then for moderately disabled people the long run effect of disability is given by $-0.627+(-0.655+0.514)=$ approximately -0.8 life satisfaction points. For severely disabled people, the sum of the life satisfaction coefficients is $-0.959+(-$ $0.655+0.557)=$ approximately -1.1 life satisfaction points. These random-effects specification thus do not show adaptation.

In a fixed-effects specification, by contrast, there is much stronger empirical support for adaptation.

Column 3 in Table 1 produces the following results for, say, a person continuously disabled for three periods. For moderately disabled people who have suffered that disability in all of those previous three years, the long run effect of disability is given by $-0.407+(-0.055+0.266)=$ approximately 0.2 life satisfaction points. By contrast, the immediate or impact effect of moderate disability is determined solely by the coefficient of -0.407 on Moderately Disabled, and thus is approximately -0.4 life satisfaction points. Hedonic adaptation here is therefore of the order of $50 \%$.

For severely disabled people, in column 3 of Table 1, the long run effect is larger: it is determined by the sum of the life satisfaction coefficients $-0.600+(-0.055+0.249)=$ approximately -0.4 life satisfaction points. By contrast, the initial impact effect of 
severe disability is determined solely by the coefficient of -0.600 on Severely Disabled. Adaptation to severe disability here is thus of the order of a little over $30 \%$.

Hence there is evidence, in this data set, of partial hedonic adaptation. Loosely speaking, we see approximately half-way adaptation to moderate disability, and roughly one-third adaptation to severe disability. In work not reported here, we have found that the spirit of these conclusions is not greatly affected by the exact choice of lags used in the econometric work.

To be sure that such results are not being driven by individuals who are in the panel only briefly, we re-do the calculations, in the right-hand half of Table 1, on a smaller balanced panel. The estimated size of adaptation rises. In the fixed-effects specification of column 6 of Table 1, it is not possible to reject the null of approximately $100 \%$ adaptation to moderate disability, and there is now more than $60 \%$ adaptation to severe disablement (the numbers in this later case are in the long run $-0.639+(-0.027+0.436)=$ approximately -0.2 life satisfaction points $)$.

Experiments using for example a lag of t-6 produced similar results, except that the long-run decline in well-being after a disability shock was sometimes slightly less (by around 0.1 life satisfaction points). For example, in the equivalent to column 2 of Table 1, the t-6 random-effects specification implied a fall in life satisfaction points from severe disability of -0.872 rather than of -1.057 .

We checked also for an interaction term between income and disability. However, the null of zero on its coefficient could not be rejected. 13

This picture of high adaptation to disability is reinforced by German panel results, which, as suggested by a referee, can allow greater control for the extent of disability.

\footnotetext{
13 Although an exact comparison is not possible, a related result of Smith et al (2005), on a sample of adults approaching retirement age, is of interest. The authors argue that assets -- on which we do not have data -- can psychologically cushion people who encounter a period of disability. Assets and educational level are likely to be systematically positively correlated. Smith et al (2005) also provide evidence that disability lowers psychological well-being, although an exact comparison with our results does not seem possible because the authors do not distinguish between one period of disability and continuing disability.
} 
These equations are presented in an appendix. We also checked our findings using multi-level modelling; the results are available on request.

\section{Compensation and Disability}

Hedonic adaptation has practical implications. One, potentially, is in courts of law.

Consider a judge who, in a world where people exhibit partial hedonic adaptation, is trying to decide on the necessary level of compensation to award someone who has negligently suffered a bad life event, L. Initially, the judge must estimate the immediate drop in happiness caused by L upon the person's life. Then the judge must make an adjustment for the way the person's utility may automatically rebound. Legal scholars have written little on this issue, and judges use mechanical rules of thumb with conceptual foundations that are, at best, ad hoc (see, for example, pages 345-347 of Elliott and Quinn, 2005). 14

In Table 1, a variable has been included for real income. It enters positively; richer people report higher levels of life satisfaction. In the fixed-effects equations, the standard error becomes large, although the German appendix results are better determined.

In the spirit of the earlier analytical framework, this suggests a simple calculation in which a kind of compensating variation can be calculated directly. Like Clark and Oswald (2002), Groot et al (2004), Van Praag and Ferrer-i-Carbonell (2004) and Powdthavee (2008), we can ask the conceptual question: how much extra real income would be required to exactly compensate someone for a change in another of the influences ${ }^{15}$ upon well-being (in this particular case, for disability)?

\footnotetext{
14 However, in a somewhat related spirit, Posner (2000) argues persuasively for a better understanding of the emotions. Posner and Sunstein (2005) discuss similar ideas. Some time after our initial 2005 working paper was written, we became aware of the interesting work, now published, of Bagenstos and Schlanger (2007).

15 Appropriate hedonic compensation for bereavement is studied in Oswald and Powdthavee (2008).
} 
Our earlier working paper Oswald and Powdthavee (2005) gives illustrative compensation figures. Because it is difficult to purge all endogeneity from the income variable, we have, at a referee's suggestion, omitted actual compensation amounts here. But the general idea remains one that may eventually have practical application for lawyers and judges: happiness equations potentially give a way of estimating the sums of money required to compensate people for bad life events; it is possible, within such equations, to allow for hedonic adaptation; and, as in the model at the start of the paper, such adaptation will in general reduce the sums required.

\section{$\underline{\text { 8. Discussion }}$}

One concern is that a human being's physical health may automatically rebound, so well-being also will, and that is not what is generally meant by hedonic adaptation. To try to get around this, the paper's focus is upon individuals who continue to report themselves in the disabled category. Yet some people who suffer a permanent bad event like disabling illness may gradually recover psychologically as their physical health itself returns -- and the blind might, say, learn to read Braille and then mark themselves as happier in the next survey. This is not necessarily a strong objection. Within our disabled sample, a reverse tendency will also be at work. There will be individuals whose health, for reasons of an increasingly debilitating condition, is worsening. Ideally we would control for the severity of disability and German results in the appendix go some way toward that.

Second, the use of life-satisfaction scores may be open to objection. Some proxyutility measure, however, is required. Life satisfaction numbers carry with them -- it could be argued -- the possibility that human beings alter their reported satisfaction score, artificially, merely because their reference level alters. For example, a disabled person might, ex post, begin to compare herself subconsciously to a different standard about what counts as being satisfied (one could imagine: 'I guess I am a happy 7, bearing in mind that I am disabled'). This is a point about the language of expressed satisfaction. There is probably no way to reject such concerns definitively, but one objection to it is that in our data there is a continuing negative effect from longstanding disability; this seems inconsistent with the claim that disabled people fundamentally rescale their use of language. Finally, as a variant, re-doing the paper's 
equations and figures using a so-called GHQ psychiatric distress score taken from the same data set also shows evidence of a bounce-back in mental well-being. These results are available upon request.

Third, it might be argued that disability is endogenous: unhappy people may overreport ill-health and disability. It would not be correct, however, to suggest that the paper's correlations are due to any simple version of such an argument. The fixedeffects estimates imply that there is more going on in the data than an omitted variable for pessimism.

Fourth, as usual, attrition from the panel could be problematic. This is difficult to correct comprehensively. It might be argued that some of the most severely disabled individuals die disproportionately often, or move into hospital, and that this would give the mere appearance of adaptation because of a composition effect among those who remain in the sample. However, when we estimated a logit -- with fixed effects - on the chance of dropping out of our sample, we found that becoming disabled does not lead to a statistically significantly higher probability of dropping out next period. Moreover, an attrition argument cannot explain the recovery pattern among those tracked in Figures 1 and 2. Finally, the level of life satisfaction is not a significant predictor of who goes on to disappear from the panel in the next period.

Fifth, income is not exogenous and any well-being gain from money may itself wear off. Short of having randomly assigned income, as in lottery windfalls, there is little that can be definitively done about the endogeneity of incomes in standard data sets. However, if instruments could be found, it might be possible to adjust the estimated income parameters in a conventional econometric way. If there is habituation-toincome, as DiTella, Haisken and MacCulloch (2005) argue, then that can be incorporated both into the general method set and into actual financial compensation settlements. This point is likely to stimulate future work in the area. Nevertheless, when the life satisfaction equations in tables like Table 1 are re-estimated with lagged levels of income as extra regressors, which we have done as a check on the calculations, a positive steady-state effect of income (of approximately the same size) is found. In this data set, we do not find strong evidence of habituation to income. 
Other arguments and counter-arguments are discussed in the longer working-paper version of this paper.

\section{$\underline{\text { 9. Conclusions }}$}

This paper studies shocks to utility and how human beings respond to them. It presents longitudinal evidence consistent with the existence of hedonic adaptation. Our focus is on disability, but the paper's message is potentially a more general one. We outline methods for the study of adaptation and report a variety of econometric specifications. Such methods may eventually come to have practical applications, such as in courts of law.

The data do not support the idea that after tragedy there is routinely a return to the old well-being level: here in illustrative calculations we estimate the degree of adaptation to be of the order of $30 \%$ to $50 \%$. These results could be read alongside the old, and highly-cited, cross-section work of Brickman et al (1978), which has come to be seen by many writers as claiming that human beings completely recover psychologically from even extreme disability ${ }^{16}$. Those cross-sectional results have played an influential role in social science; but our empirical conclusions are rather different.

We began by noting a divide between the psychology and economics journals. The above results seem to point to a middle ground -- partial hedonic adaptation -between the traditional economist's model of $0 \%$ adaptation and the extreme $100 \%$ adaptation model advocated by some authors in the psychology literature. It may be that the two social-science disciplines can converge in their thinking.

\footnotetext{
16 As noted earlier, Lucas (2007) concludes at the other extreme: that there is zero adaptation. We have been unable to resolve all the differences between his analysis and ours, which began independently from one another, and future work will probably have to address this.
} 


\section{$\underline{\text { References }}$}

Argyle, M., 1989. The Psychology of Happiness. London: Routledge.

Bagenstos, S.R., Schlanger, M., 2007. Hedonic damages, hedonic adaptation and disability. Vanderbilt Law Review 60, 745-797.

Blanchflower, D.G., Oswald, A.J., 2004. Well-being over time in Britain and the USA. Journal of Public Economics 88, 1359-1386.

Brickman, P., Coates, D., Janoff-Bulman, R., 1978. Lottery winners and accident victims - is happiness relative? Journal of Personality and Social Psychology 36, 917-927.

Burchardt, T., 2005. Are one man's rags another man's riches? Identifying adaptive expectations using panel data. Social Indicators Research 74, 57-102.

Chase, B. W., Cornille, T.A., English, R.W., 2000. Life satisfaction among persons with spinal cord injuries. Journal of Rehabilitation 66, 14-20.

Clark, A.E., 1999. Are wages habit-forming? Evidence from micro data, Journal of Economic Behavior and Organization 39, 179-200.

Clark, A. E., Diener, E., Georgellis, Y., Lucas, R. E., 2007. Lags and leads in life satisfaction: A test of the baseline hypothesis. Economic Journal, forthcoming.

Clark, A.E., Georgellis, Y., Sanfey, P., 2001. Scarring: The psychological impact of past unemployment. Economica 68, 221-241.

Clark, A.E., Oswald, A.J., 1994. Unhappiness and unemployment. Economic Journal 104, 648-659.

Clark, A.E., Oswald, A.J., 2002. A simple statistical method for measuring how life events affect happiness. International Journal of Epidemiology 31(6), 11391144.

Diener, E., Suh, E.M., Lucas, R.E., Smith, H.L., 1999. Subjective well-being: Three decades of progress. Psychological Bulletin 125(2), 276-302.

Di Tella, R., MacCulloch, R.J., Oswald, A.J., 2001. Preferences over inflation and unemployment: Evidence from surveys of happiness. American Economic Review 91, 335-341.

Di Tella, R., MacCulloch, R.J., Oswald, A.J., 2003. The macroeconomics of happiness. Review of Economics and Statistics 85, 809-827.

Di Tella, R., Haisken, J., Macculloch, R., 2005. Happiness adaptation to income and to status in an individual panel, working paper, Harvard Business School.

Easterlin, R.A., 2001. Income and happiness: Towards a unified theory. Economic Journal 111, 465-484.

Easterlin, R.A., 2003. Explaining happiness. Proceedings of the National Academy of Sciences 100, 11176-11183.

Easterlin, R.A., 2005. A puzzle for adaptive theory. Journal of Economic Behavior and Organization 56, 513-521.

Easterlin, R.A., Reynolds, S.L., Shemyakina, O., Saito, Y., 2006. Do people adapt fully to adverse changes in health? Working paper, University of Southern California.

Elliott, C., Quinn, R., 2005. Tort Law. Pearson Education: Longman, London and Boston.

Ferrer-i-Carbonell A., 2005. Income and well-being: An empirical analysis of the comparison income effect. Journal of Public Economics 89, 997-1019.

Ferrer-i-Carbonell A., Van Praag B.M.S., 2002. The subjective costs of health losses due to chronic diseases. An alternative model for monetary appraisal. Health Economics 11, 709-722. 
Frederick, S., Loewenstein, G., 1999. Hedonic adaptation. In E. Diener, N. Schwarz and D. Kahneman (Eds.) Hedonic Psychology: Scientific Approaches to Enjoyment, Suffering, and Well-being. Russell Sage Foundation. New York. 302-329.

Frey, B.S., Meier, S., 2004. Social comparisons and pro-social behaviour: Testing conditional cooperation in a field experiment. American Economic Review 94(5), 1717-1722.

Frey, B. S., Stutzer, A., 2002. Happiness and Economics. Princeton, USA:

Fujita, F., Diener, E., 2005. Life satisfaction set point: stability and change. Journal of Personality and Social Psychology 88(1), 158-164.

Gilbert, D.T., Driver-Linn, E., Wilson, T.D., 2002. The trouble with Vronsky: Impact bias in the forecasting of future affective states. In L. Feldman-Barrett \& P. Salvoney (Eds.) The Wisdom of Feeling, Guilford, New York.

Gilbert, D. T., Pinel, E. C., Wilson, T. D., Blumberg, S. J., Wheatley, T., 1998. Immune neglect: A source of durability bias in affective forecasting. Journal of Personality and Social Psychology 75, 617-638.

Gilboa, I., Schmeidler, D., 2001. A cognitive model of individual well-being. Social Choice and Welfare 18, 269-288.

Graham, L., Oswald, A.J., 2005. Hedonic capital. Working paper, University College London.

Groot, W., 2000. Adaptation and scale of reference bias in self-assessments of quality of life. Journal of Health Economics 19, 403-420.

Groot, W., Van den Brink, M., 2000, Life-satisfaction and preference drift. Social Indicators Research 50, 315-328.

Groot, W., van den Brink, H.T.M., Plug, E., 2004. Money for health: the equivalent variation of cardiovascular diseases. Health Economics 13, 859-872.

Gruber, J., 2000. Disability insurance benefits and labor supply. Journal of Political Economy 108, 1162-1183.

Haisken-De New, J. P., Frick, R., 1998. Desktop companion to the German SocioEconomic Panel Study (GSOEP). Berlin: German Institute for Economic Research (DIW).

Kahneman, D., Sugden, R., 2005. Experienced utility as a standard of policy evaluation. Environmental and Resource Economics 32, 161-181.

Kreft, I., De Leeuw, J., (1998). Introducing multilevel modeling. Thousand Oaks, CA: Sage Publications.

Layard, R., 2005. Happiness: Lessons from a New Science, Allen Lane, London.

Linley, P.A., Joseph, S., 2004. Positive change following trauma and adversity: A review. Journal of Traumatic Stress 17, 11-21.

Lucas, R.E., 2005. Time does not heal all wounds: A longitudinal study of reaction and adaptation to divorce. Psychological Science 16, 945-950.

Lucas, R.E., 2007. Long-term disability is associated with lasting changes in subjective well-being: Evidence from two nationally representative longitudinal studies. Journal of Personality and Social Psychology 92, 717-730.

Lucas, R.E., Clark, A. E., Diener, E., Georgellis, Y., 2003. Re-examining adaptation and the setpoint model of happiness: Reactions to changes in marital status. Journal of Personality and Social Psychology 84 (3), 527-539.

Lucas, R.E., Clark, A. E., Georgellis, Y., Diener, E., 2004. Unemployment alters the set point for life satisfaction. Psychological Science 15 (1), 8-13.

Luttmer, E.F.P., 2005. Neighbors as negatives: Relative earnings and well-being. Quarterly Journal of Economics 120, 963-1002. 
Lyubomirsky, S., Sheldon, K.M., Schkade, D., 2005. Pursuing happiness: The architecture of sustainable change. Review of General Psychology 9, 111-131.

Menzel, P., Dolan, P., Richardson, J. el al., 2002. The role of adaptation to disability and disease in health state valuation: a preliminary normative analysis. Social Science and Medicine 55 (12), 2149-2158.

Oswald, A.J., 1997. Happiness and economic performance. Economic Journal 107, 1815-1831.

Oswald, A.J., Powdthavee, N., 2005. Does happiness adapt? A longitudinal study of disability with implications for economists and judges. Working paper, Warwick University (also available as IZA working paper \#2208, 2006).

Oswald, A.J., Powdthavee, N., 2008. Death, happiness, and the calculation of compensatory damages. Journal of Legal Studies, forthcoming.

Posner, E. A., 2000. Law and the emotions. University of Chicago Law \& Economics, Olin Working Paper No. 103.

Posner, E.A., Sunstein, C.R., 2005. Dollars and death. University of Chicago Law Review 72, 537-598.

Powdthavee, N., 2007. Putting a price tag on friends, relatives and neighbours: Using surveys of life satisfaction to value social relationships, Journal of Socioeconomics, forthcoming.

Rayo, L., Becker, G.S., 2007. Evolutionary efficiency and happiness. Journal of Political Economy 115, 302-337.

Riis J., Loewenstein G., Baron J., Jepson C., 2005. Ignorance of hedonic adaptation to hemodialysis: A study using ecological momentary assessment. Journal of Experimental Psychology: General 134 (1), 3-9.

Senik, C., 2004. When information dominates comparison - Learning from Russian subjective panel data. Journal of Public Economics 88, 2099-2123.

Smith, D.M., Langa, K.M., Kabeto, M.U., Ubel, P.A., 2005. Health, wealth and happiness. Psychological Science 16, 663-666.

Stutzer, A. 2004., The role of income aspirations in individual happiness. Journal of Economic Behavior and Organization 54, 89-109.

Taylor, M. F., Brice, J., Buck, N., Prentice-Lane, E., 2002. British Household Panel Survey User Manual. Colchester: University of Essex.

Ubel, P.A., Loewenstein, G., Jepson, C., 2005. Disability and sunshine: Can hedonic predictions be improved by drawing attention to focusing illusions or emotional adaptation? Journal of Experimental Psychology: Appl 11, 111-123.

Van Praag, B., Ferrer-I-Carbonell, A., 2004. Happiness Quantified: A Satisfaction Calculus Approach, Oxford University Press, Oxford.

Ville, I., Ravaud, J.F., 2001. Subjective well-being and severe motor impairments: The Tetrafigap Survey on the long-term outcome of tetraplegic spinal cord injured persons. Social Science and Medicine 52, 369-384.

Wilson, T.D., Gilbert, D.T., 2005. A model of affective adaptation, working paper, University of Virginia and Harvard University.

Winkelmann, L., Winkelmann, R., 1998. Why are the unemployed so unhappy? Evidence from panel data. Economica 65, 1-15.

Wu S., 2001. Adapting to heart conditions: a test of the hedonic treadmill. Journal of Health Economics 20, 495-508.

Zimmermann, A., Easterlin, R.A., 2006. Happily ever after? Cohabitation, marriage, divorce, and happiness in Germany. Population and Development Review 32, $511-528$. 


\section{Figure 1}

\section{The Life-Satisfaction Path of Those Who Entered Disability at Time $T$ and Remained Disabled in $T+1$ and $T+2$}

BHPS data 1996-2005

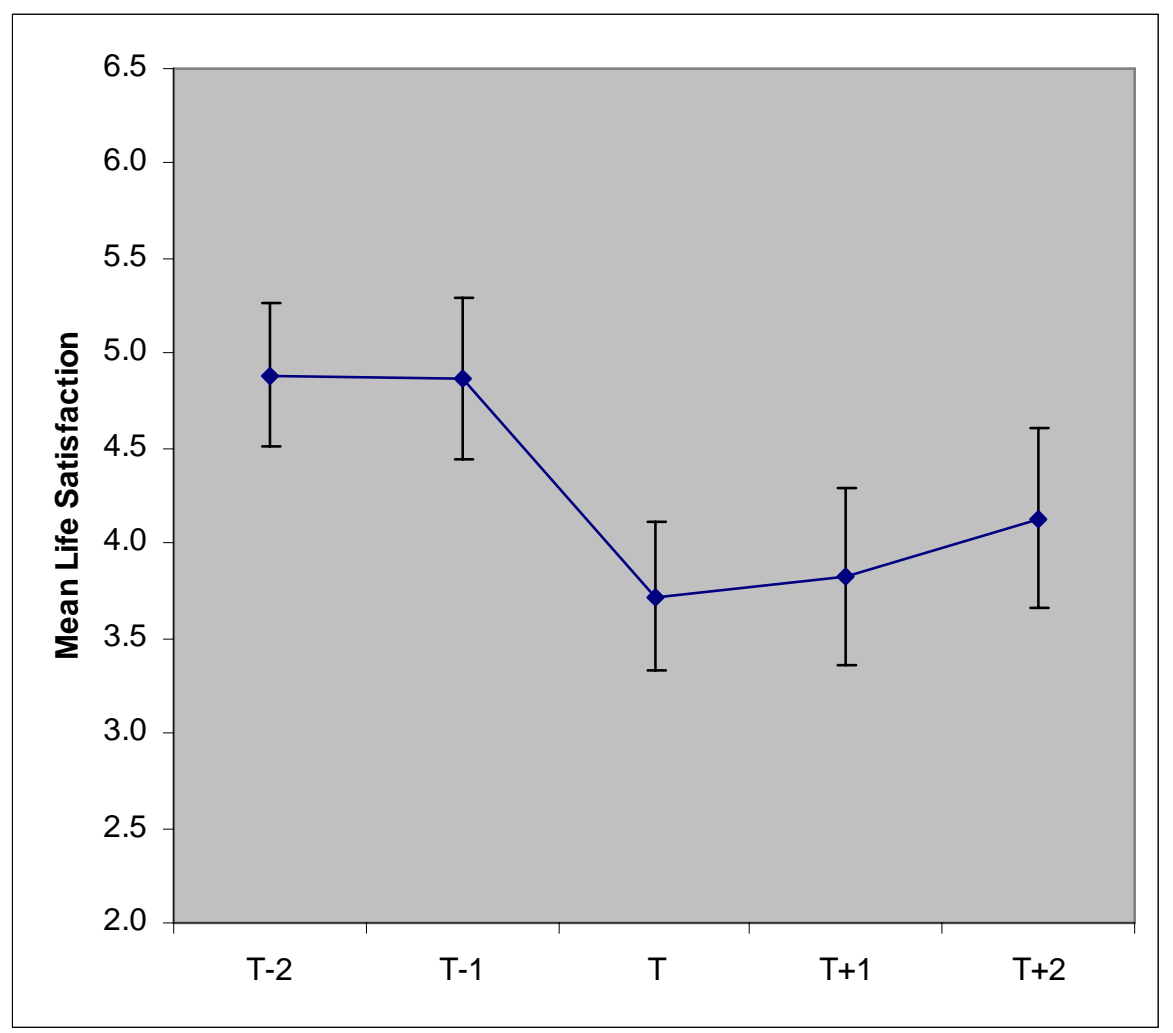

Note: There were 61 individuals who became disabled at time $T$ and remained disabled in $T+1$ and $T+2$. The $t$-test statistics [p-value] of whether the mean life satisfaction of the individual is equal are 3.119 [0.002] (between T-1 and T), -0.261 [0.795] (between T and T+1), and -1.072 [0.286] (between T and T+2). The time periods are years.

These are raw data; they are not regression-corrected.

4-standard-error bands (95\% C.I.) are reported: two s.e. above and two below. 


\section{Figure 2}

The Life-Satisfaction Path of Those Who Became Disabled From An Accident at Time $T$ and Remained Disabled in $T+1$ and $T+2$

BHPS data 1996-2005

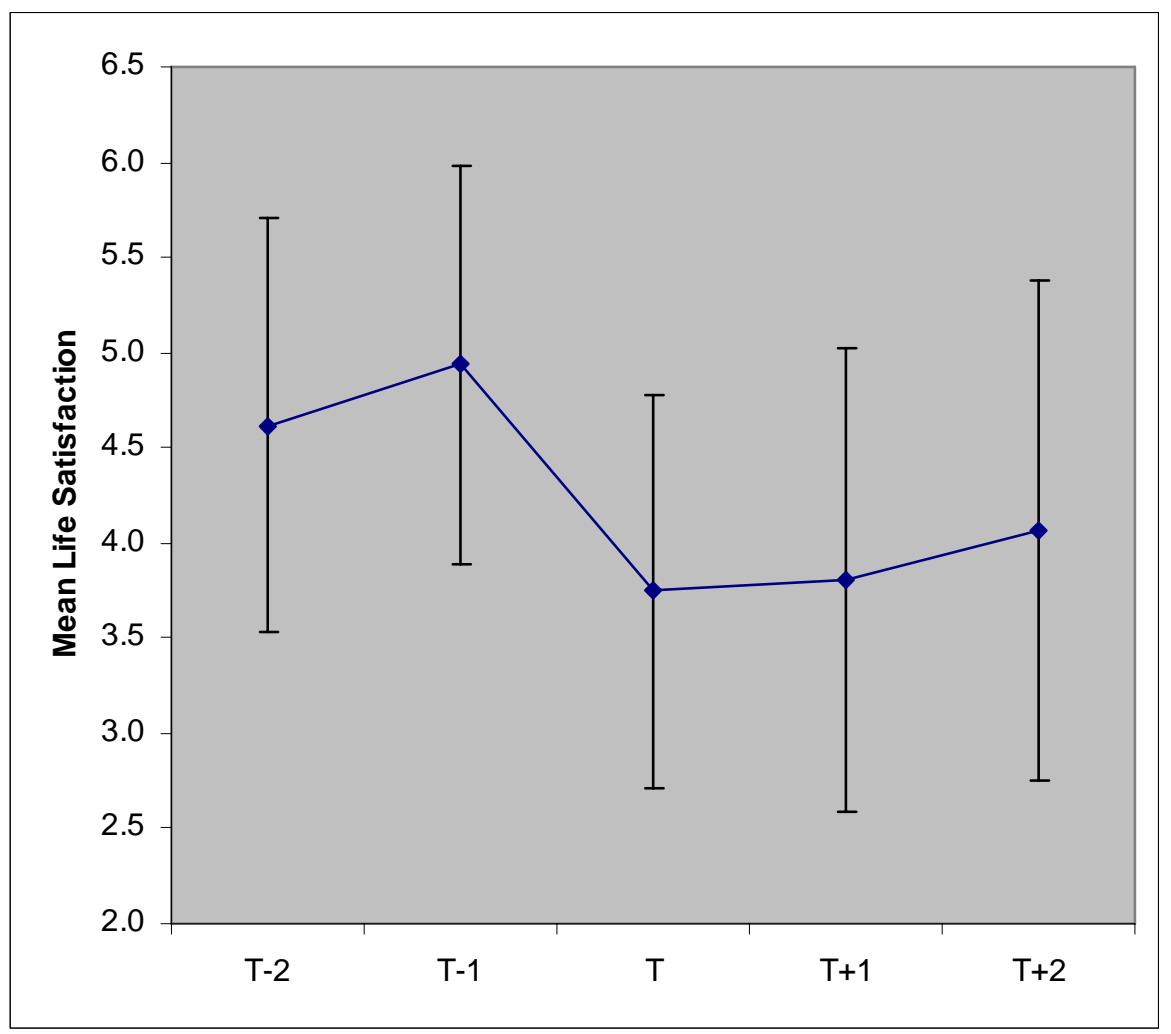

Note: There were 10 individuals who became disabled from an accident at time $T$ and remained disabled in $T+1$ and $T+2$. The $t$-test statistics [p-value] of whether the mean life satisfaction of the individual is equal are 2.073 [0.052] (between T-1 and T), -0.651 [0.523] (between T and T+1), and -0.905 [0.377] (between T and $\mathrm{T}+2)$. The time periods are years.

These are raw data; they are not regression-corrected.

4-standard-error bands (95\% C.I.) are reported: two s.e. above and two below. 


\section{Table 1}

\section{Life-Satisfaction Regression Equations with Past-Disability Variables: BHPS Data 1996-2004}

\begin{tabular}{|c|c|c|c|c|c|c|}
\hline & \multicolumn{3}{|c|}{$\begin{array}{c}\text { Unbalanced } \\
\text { panel }\end{array}$} & \multicolumn{3}{|c|}{$\begin{array}{c}\text { Balanced } \\
\text { panel }\end{array}$} \\
\hline & RE & $\mathbf{R E}$ & FE & RE & $\mathbf{R E}$ & FE \\
\hline \multirow[t]{2}{*}{ Disabled } & -0.880 & & & -0.780 & & \\
\hline & {$[0.041]^{* *}$} & & & {$[0.066]^{* *}$} & & \\
\hline \multirow[t]{2}{*}{ Moderately disabled } & & -0.627 & -0.407 & & -0.495 & -0.354 \\
\hline & & {$[0.081]^{* *}$} & {$[0.087]^{* *}$} & & {$[0.125]^{* *}$} & {$[0.128]^{* *}$} \\
\hline \multirow[t]{2}{*}{ Severely disabled } & & -0.959 & -0.600 & & -0.878 & -0.639 \\
\hline & & {$[0.047]^{* *}$} & {$[0.054]^{* *}$} & & {$[0.075]^{* *}$} & {$[0.079]^{* *}$} \\
\hline \multirow[t]{2}{*}{ Ratio of time spent disabled (from t-3 to $t-1$ ) } & -0.651 & -0.655 & -0.055 & -0.440 & -0.439 & -0.027 \\
\hline & {$[0.054]^{* *}$} & {$[0.053]^{* *}$} & {$[0.068]$} & {$[0.086]^{* *}$} & {$[0.085]^{* *}$} & {$[0.099]$} \\
\hline \multirow[t]{2}{*}{ Disabled* Ratio of time spent disabled } & 0.525 & & & 0.556 & & \\
\hline & {$[0.076]^{* *}$} & & & {$[0.119]^{* *}$} & & \\
\hline \multirow[t]{2}{*}{ Moderately disabled* Ratio of time spent disabled } & & 0.514 & 0.266 & & 0.515 & 0.347 \\
\hline & & {$[0.128]^{* *}$} & [0.140] & & {$[0.201]^{*}$} & [0.208] \\
\hline \multirow[t]{2}{*}{ Severely disabled $*$ Ratio of time spent disabled } & & 0.557 & 0.249 & & 0.609 & 0.436 \\
\hline & & {$[0.080]^{* *}$} & {$[0.089]^{* *}$} & & {$[0.125]^{* *}$} & {$[0.131]^{* *}$} \\
\hline \multicolumn{7}{|l|}{$\begin{array}{l}\text { The implied well-being effect after any adaptation to } \\
\text { disability: }\end{array}$} \\
\hline \multirow[t]{2}{*}{3 years of being disabled } & -1.006 & & & -0.664 & & \\
\hline & {$[0.040] * *$} & & & {$[0.066] * *$} & & \\
\hline \multirow[t]{2}{*}{3 years of being moderately disabled } & & -0.767 & -0.196 & & -0.420 & -0.035 \\
\hline & & {$[0.077]^{* *}$} & {$[0.098]^{*}$} & & {$[0.127]^{* *}$} & {$[0.146]$} \\
\hline \multirow[t]{2}{*}{3 years of being severely disabled } & & -1.057 & -0.405 & & -0.707 & -0.232 \\
\hline & & {$[0.042]^{* *}$} & {$[0.067]^{* *}$} & & {$[0.068]^{* *}$} & {$[0.096] * *$} \\
\hline
\end{tabular}

\begin{tabular}{|c|c|c|c|c|c|c|}
\hline \multicolumn{7}{|c|}{ Personal and household controls in these equations } \\
\hline \multirow[t]{2}{*}{ Male } & -0.027 & -0.028 & & 0.018 & 0.018 & \\
\hline & {$[0.017]$} & {$[0.017]$} & & {$[0.027]$} & {$[0.027]$} & \\
\hline \multirow[t]{2}{*}{ Age } & -0.008 & -0.008 & & -0.007 & -0.007 & \\
\hline & {$[0.003]^{* *}$} & {$[0.003]^{* *}$} & & [0.005] & [0.005] & \\
\hline \multirow[t]{2}{*}{ Age-sq/100 } & 0.012 & 0.013 & -0.031 & 0.014 & 0.014 & -0.013 \\
\hline & {$[0.003]^{* *}$} & {$[0.003]^{* *}$} & {$[0.005]^{* *}$} & {$[0.005]^{* *}$} & {$[0.005]^{* *}$} & [0.008] \\
\hline \multirow[t]{2}{*}{ Log of real household income per capita } & 0.042 & 0.043 & 0.015 & 0.044 & 0.043 & 0.019 \\
\hline & {$[0.008]^{* *}$} & {$[0.008]^{* *}$} & [0.009] & {$[0.012]^{* *}$} & {$[0.012]^{* *}$} & [0.013] \\
\hline \multirow[t]{2}{*}{ Living as couple } & -0.057 & -0.059 & 0.034 & -0.078 & -0.079 & 0.017 \\
\hline & {$[0.020]^{* *}$} & {$[0.020]^{* *}$} & {$[0.028]$} & {$[0.034]^{*}$} & {$[0.034]^{*}$} & [0.044] \\
\hline \multirow[t]{2}{*}{ Widowed } & -0.350 & -0.351 & -0.345 & -0.316 & -0.317 & -0.276 \\
\hline & {$[0.029]^{* *}$} & {$[0.029]^{* *}$} & {$[0.045]^{* *}$} & {$[0.044]^{* *}$} & {$[0.044]^{* *}$} & {$[0.061]^{* *}$} \\
\hline \multirow[t]{2}{*}{ Divorced } & -0.465 & -0.467 & -0.291 & -0.425 & -0.427 & -0.251 \\
\hline & {$[0.027]^{* *}$} & {$[0.027]^{* *}$} & {$[0.039]^{* *}$} & {$[0.041]^{* *}$} & {$[0.041]^{* *}$} & {$[0.053]^{* *}$} \\
\hline \multirow[t]{2}{*}{ Separated } & -0.605 & -0.605 & -0.457 & -0.607 & -0.609 & -0.475 \\
\hline & {$[0.036]^{* *}$} & {$[0.036]^{* *}$} & {$[0.042]^{* *}$} & {$[0.053]^{* *}$} & {$[0.053]^{* *}$} & {$[0.058]^{* *}$} \\
\hline \multirow[t]{2}{*}{ Never married } & -0.253 & -0.256 & -0.087 & -0.341 & -0.342 & -0.165 \\
\hline & {$[0.023]^{* *}$} & {$[0.023]^{* *}$} & {$[0.036]^{*}$} & {$[0.042]^{* *}$} & {$[0.042]^{* *}$} & {$[0.063]^{* *}$} \\
\hline \multirow[t]{2}{*}{ Unemployed } & -0.366 & -0.363 & -0.286 & -0.287 & -0.287 & -0.241 \\
\hline & {$[0.027]^{* *}$} & {$[0.027]^{* *}$} & {$[0.030]^{* *}$} & {$[0.046]^{* *}$} & {$[0.046]^{* *}$} & {$[0.048]^{* *}$} \\
\hline \multirow[t]{2}{*}{ Retired } & 0.036 & 0.034 & 0.022 & 0.080 & 0.078 & 0.053 \\
\hline & [0.022] & [0.022] & {$[0.026]$} & {$[0.030]^{* *}$} & {$[0.030]^{* *}$} & [0.034] \\
\hline \multirow[t]{2}{*}{ Look after home } & -0.103 & -0.103 & -0.072 & -0.038 & -0.038 & -0.038 \\
\hline & {$[0.021]^{* *}$} & {$[0.021]^{* *}$} & {$[0.025]^{* *}$} & [0.031] & [0.031] & [0.034] \\
\hline \multirow[t]{2}{*}{ Student } & 0.109 & 0.110 & 0.120 & -0.010 & -0.009 & -0.015 \\
\hline & {$[0.037]^{* *}$} & {$[0.037]^{* *}$} & {$[0.043]^{* *}$} & [0.087] & [0.087] & [0.091] \\
\hline
\end{tabular}




\begin{tabular}{|c|c|c|c|c|c|c|}
\hline Education: A-level & $\begin{array}{c}-0.030 \\
{[0.020]}\end{array}$ & $\begin{array}{c}-0.030 \\
{[0.020]}\end{array}$ & $\begin{array}{c}0.013 \\
{[0.055]}\end{array}$ & $\begin{array}{c}-0.028 \\
{[0.033]}\end{array}$ & $\begin{array}{c}-0.029 \\
{[0.033]}\end{array}$ & $\begin{array}{c}0.043 \\
{[0.079]}\end{array}$ \\
\hline Education: University & $\begin{array}{c}-0.012 \\
{[0.021]}\end{array}$ & $\begin{array}{c}-0.012 \\
{[0.020]}\end{array}$ & $\begin{array}{c}0.064 \\
{[0.051]}\end{array}$ & $\begin{array}{c}-0.012 \\
{[0.033]}\end{array}$ & $\begin{array}{c}-0.013 \\
{[0.033]}\end{array}$ & $\begin{array}{c}0.111 \\
{[0.072]}\end{array}$ \\
\hline Household size & $\begin{array}{c}-0.033 \\
{[0.007]^{* *}}\end{array}$ & $\begin{array}{c}-0.033 \\
{[0.007]^{* *}}\end{array}$ & $\begin{array}{c}-0.046 \\
{[0.009]^{* *}}\end{array}$ & $\begin{array}{c}-0.057 \\
{[0.012]^{* *}}\end{array}$ & $\begin{array}{c}-0.057 \\
{[0.012]^{* *}}\end{array}$ & $\begin{array}{c}-0.077 \\
{[0.014]^{* *}}\end{array}$ \\
\hline Own home outright & $\begin{array}{c}0.126 \\
{[0.015]^{* *}}\end{array}$ & $\begin{array}{c}0.126 \\
{[0.015]^{* *}}\end{array}$ & $\begin{array}{c}0.065 \\
{[0.020]^{* *}}\end{array}$ & $\begin{array}{c}0.102 \\
{[0.023]^{* *}}\end{array}$ & $\begin{array}{c}0.102 \\
{[0.023]^{* *}}\end{array}$ & $\begin{array}{c}0.047 \\
{[0.028]}\end{array}$ \\
\hline Number of children & $\begin{array}{c}-0.008 \\
{[0.009]}\end{array}$ & $\begin{array}{c}-0.008 \\
{[0.009]}\end{array}$ & $\begin{array}{c}0.021 \\
{[0.011]}\end{array}$ & $\begin{array}{c}0.013 \\
{[0.014]}\end{array}$ & $\begin{array}{c}0.013 \\
{[0.014]}\end{array}$ & $\begin{array}{c}0.024 \\
{[0.016]}\end{array}$ \\
\hline Constant & $\begin{array}{c}5.185 \\
{[0.111]^{* *}}\end{array}$ & $\begin{array}{c}5.185 \\
{[0.111]^{* *}}\end{array}$ & $\begin{array}{c}5.972 \\
{[0.156]^{* *}}\end{array}$ & $\begin{array}{c}5.058 \\
{[0.203]^{* *}}\end{array}$ & $\begin{array}{c}5.063 \\
{[0.203]^{* *}}\end{array}$ & $\begin{array}{c}5.675 \\
{[0.296]^{* *}}\end{array}$ \\
\hline Regional dummies & Yes & Yes & Yes & Yes & Yes & Yes \\
\hline Year dummies & Yes & Yes & Yes & Yes & Yes & Yes \\
\hline Observations & 64243 & 64243 & 64243 & 27903 & 27903 & 27903 \\
\hline Number of persons & 16836 & 16836 & 16836 & 4774 & 4774 & 4774 \\
\hline R2_within & 0.0124 & 0.0125 & 0.0163 & 0.0122 & 0.0125 & 0.0152 \\
\hline
\end{tabular}

Standard errors in brackets

* significant at 5\%; ** significant at $1 \%$

\section{Notes:}

Life satisfaction is recorded on a 7-point scale, ranging from 1 “very dissatisfied” to 7 "very satisfied”.

We use the term moderately disabled for those who report being disabled but still able to do day-to-day activities, including all of the following: i) housework, ii) climb stairs, iii) dress oneself, and iv) walk for at least 10 minutes. We use the term severely disabled for those who report being disabled and who are unable to do at least one of these four things. We use the term disabled for the aggregation of moderately disabled and severely disabled.

The variable denoted 'Ratio of time spent disabled (from t-3 to t-1)' takes values of $0,0.33,0.66$, or 1.00 .

For the unbalanced panel, there are 675 observations of people who are moderately disabled but able to do day-today activities, as opposed to 3,442 observations of severely disabled individuals who are not able to do at least one of the listed day-to-day activities. For the balanced panel, there are 292 observations in the first category and 1,723 observations in the second category. Reference variables are: non-disabled, female, and no formal education.

RE stands for random-effects estimation. FE stands for fixed-effects estimation. 


\section{Appendix: A Check on German Data}

Our second data set draws upon waves 1 through 18 of the German Socio-Economic Panel (GSOEP). This is a longitudinal data set on German households (see Haisken-De New \& Frick, 1998, for a description of the study and its sample). Households are selected using multi-stage random sampling, and all members of households participate. Like the BHPS, surveys are conducted yearly using faceto-face interviews. The entire sample of the unbalanced panel contains 50,085 individuals who participate at least in one of the 18 waves. Of those, 3,711 are present in all 18 waves. Respondents in the German data were asked about their current disability status from 1984 (wave 1) onwards. There are 22,238 observations of people with disability in the unbalanced panel, and 6,744 observations in the balanced panel. They are also asked, in 15 of the 18 waves, about the degree of any disability they have. Here the question is: What is the extent of this capability reduction or handicap (in percentages) according to the most recent diagnosis? In addition to the questions on disability status and other socio-economic and demographic characteristics, respondents are asked how satisfied they are with their lives at the time of the survey. This uses a scale from 0 (very dissatisfied) to 10 (very satisfied). In this data set it is possible to adjust in a detailed way for the degree of impairment. Survey respondents describe how disabled they are on a scale that runs from 0 to 100. This is coded in Table $\mathrm{A} 1$ as the variable "\% disabled at $\mathrm{t}$ ". Its coefficient in a random effects specification is -0.004 and a fixed effects one it is -0.003 . Hence $100 \%$ disability would correspond to life satisfaction losses of -0.4 and -0.3 points respectively.

Table A1's random-effects and fixed-effects estimates again favour the view that estimated adaptation is greater once unchanging person effects are differenced out. In the final FE column of Table A1, the long run effect of extreme disability is estimated to be $-0.187-0.026+0.308-0.300-$ $0.100=$ approx. -0.3 life satisfaction points. To probe these findings, we re-estimated the German results on a sub-sample of people who stayed for the full 18 waves of the GSOEP panel. This greatly reduces the number of observations. But it has the advantage that the results are not then being driven by who enters or exits the sample. The character of the results is similar, but the estimated degree of adaptation is smaller.

In a second set of analytical results -- not reported but available upon request -- we used a multi-level modelling approach on the GSOEP panel to investigate within-person changes in life satisfaction before the first bout of disability, during the first three years of disability, and beyond (see Kreft \& DeLeeuw, 1998, for an introduction to these techniques; see Lucas et al., 2004, Lucas, 2005, Zimmerman \& Easterlin, 2006, for a more detailed discussion of the specific models used to test reaction and adaptation). Multi-level models allow for different numbers of assessment occasions for different participants (some participants entered the study after the study began or dropped out before the most recent year of study), and allow individuals to be included in the analyses regardless of when disability event occurred. Participants were selected from a larger sample if they began the study not disabled, became disabled at one point during the study, and then either remained disabled or recovered from disability for the remainder of the study. This selection strategy allows us to estimate a stable baseline period and a stable adaptation period for each individual. Of 50,085 individuals in the original unbalanced sample, only 248 met the criteria. The empirical model to be estimated can be written as followed:

$$
L S_{i t}=\beta_{0}+\beta_{1}(\text { reaction })+\beta_{2}(\text { adaptation })+\beta_{3}(\text { linear_change })+X_{i t}^{\prime} \gamma+\eta_{i}+\varepsilon_{i t} \text {, }
$$

At the within-person level of the model, life satisfaction is predicted from an intercept, a reaction dummy variable, and an adaptation dummy variable. The first of the three main periods of time surrounding the first bout of disability is the baseline period, which consists of all years at least 3 years prior to the year during which the individual became disabled. We did not include the year immediately preceding the event as part of the baseline phrase.

This multi-level modelling approach also generated evidence of hedonic adaptation. Results are available upon request. 
Appendix Table A1

Life-Satisfaction Regression Equations: GSOEP Data 1984-2003

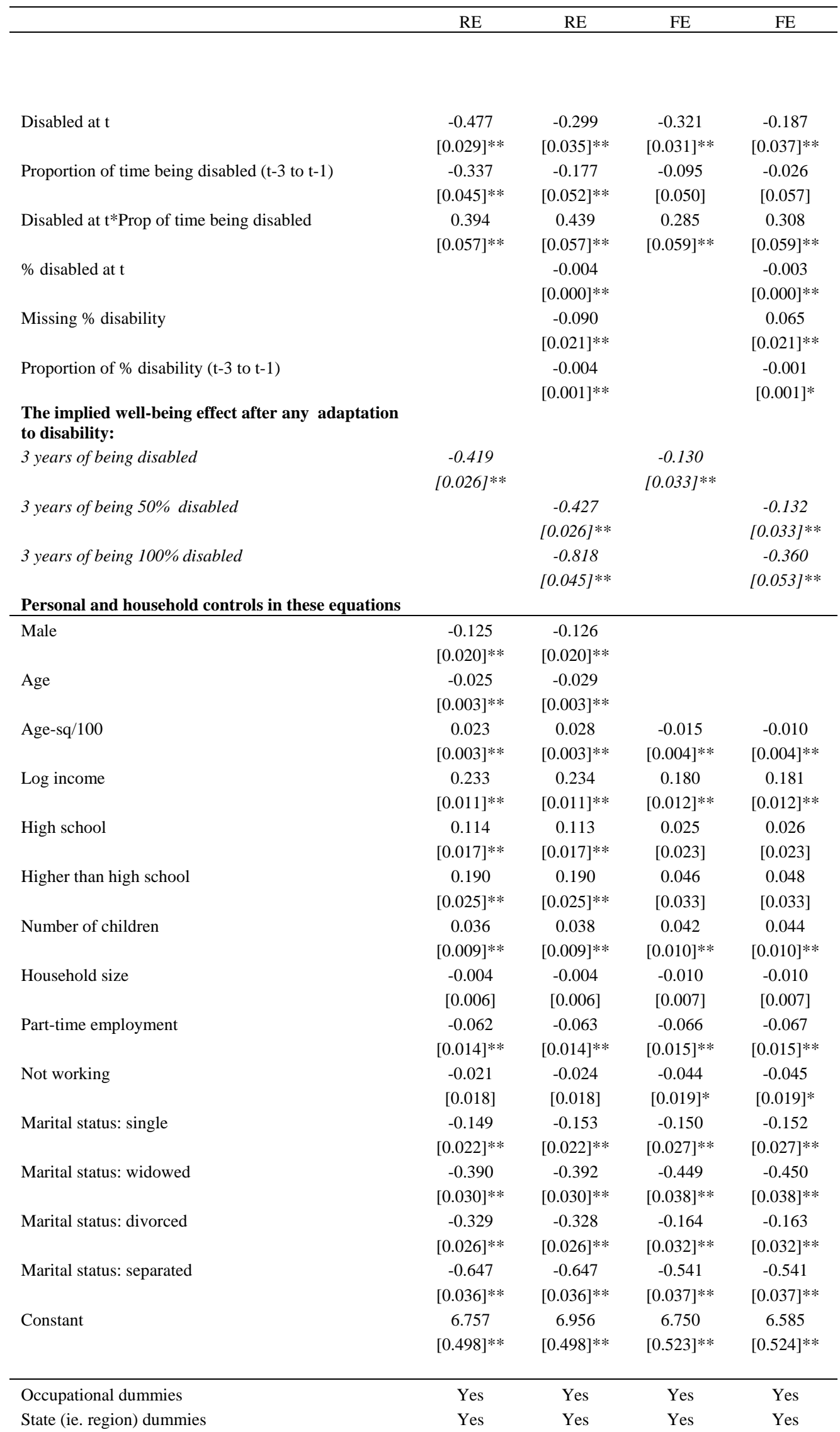




\begin{tabular}{lcccc} 
Year dummies & Yes & Yes & Yes & Yes \\
Observations & 149951 & 149951 & 149951 & 149951 \\
Number of persons & 19692 & 19692 & 19692 & 19692 \\
R2_within & 0.0216 & 0.0222 & 0.0241 & 0.0246 \\
\hline
\end{tabular}

Standard errors in brackets

* significant at $5 \%$;* significant at $1 \%$

Notes: Life satisfaction is on a scale from $0=$ least satisfied, $\ldots, 10=$ most satisfied. $\%$ disability is on a scale from $1=$ least disabled,..., 100 = most disabled. RE stands for random effects; FE stands for fixed effects. 


\section{Appendix Table A2: Descriptive Statistics on BHPS and GSOEP Data}

\begin{tabular}{|c|c|c|c|c|}
\hline & Mean & S.D. & Min & Max \\
\hline \multicolumn{5}{|l|}{ 1) British Household Panel Survey } \\
\hline Life satisfaction & 5.235 & 1.307 & 1 & 7 \\
\hline Disabled & 0.045 & 0.207 & 0 & 1 \\
\hline Moderately disabled & 0.007 & 0.085 & 0 & 1 \\
\hline Seriously disabled & 0.037 & 0.189 & 0 & 1 \\
\hline Ratio of time spent disabled (from $t-3$ to $t-1$ ) & 0.041 & 0.178 & 0 & 1 \\
\hline Ratio of time spent disabled (from t-6 to t-1) & 0.035 & 0.155 & 0 & 1 \\
\hline Male & 0.455 & 0.498 & 0 & 1 \\
\hline Age & 45.806 & 18.137 & 17 & 99 \\
\hline Age-squared/100 & 24.272 & 18.137 & 2.89 & 98.01 \\
\hline Ln(real household income per capita) & 9.020 & 0.752 & -1.89712 & 12.91238 \\
\hline Cohabit & 0.114 & 0.318 & 0 & 1 \\
\hline Widowed & 0.076 & 0.265 & 0 & 1 \\
\hline Divorced & 0.057 & 0.232 & 0 & 1 \\
\hline Separated & 0.018 & 0.133 & 0 & 1 \\
\hline Never married & 0.190 & 0.393 & 0 & 1 \\
\hline Unemployed & 0.034 & 0.182 & 0 & 1 \\
\hline Retired & 0.209 & 0.406 & 0 & 1 \\
\hline Looking after home & 0.076 & 0.265 & 0 & 1 \\
\hline Student & 0.043 & 0.202 & 0 & 1 \\
\hline Highest education: A-level & 0.399 & 0.490 & 0 & 1 \\
\hline Highest education: University & 0.327 & 0.469 & 0 & 1 \\
\hline Household size & 2.818 & 1.364 & 1 & 13 \\
\hline Own home outright & 0.260 & 0.438 & 0 & 1 \\
\hline Number of children (aged<16) & 0.607 & 0.975 & 0 & 8 \\
\hline \multicolumn{5}{|l|}{$N=64243$} \\
\hline \multicolumn{5}{|l|}{ 2) German Socio-Economic Panel } \\
\hline Life satisfaction & 7.038 & 1.869 & 0 & 10 \\
\hline Disabled & 0.084 & 0.278 & 0 & 1 \\
\hline Ratio of time spent disabled (from $t-3$ to $t-1$ ) & 0.091 & 0.271 & 0 & 1 \\
\hline Disability level & 4.256 & 16.524 & 0 & 100 \\
\hline Proportion of \% disability (t-3 to t-1) & 4.260 & 14.132 & 0 & 100 \\
\hline Male & 0.488 & 0.500 & 0 & 1 \\
\hline Age & 41.563 & 18.414 & 14 & 102 \\
\hline Age-squared/100 & 20.665 & 16.583 & 2.56 & 104.04 \\
\hline High school & 0.512 & 0.500 & 0 & 1 \\
\hline More than high school & 0.123 & 0.328 & 0 & 1 \\
\hline Part-time work & 0.441 & 0.497 & 0 & 1 \\
\hline Not working & 0.081 & 0.273 & 0 & 1 \\
\hline Marital status: single & 0.060 & 0.237 & 0 & 1 \\
\hline Marital status: widowed & 0.050 & 0.218 & 0 & 1 \\
\hline Marital status: divorced & 0.013 & 0.112 & 0 & 1 \\
\hline Marital status: separated & 0.003 & 0.053 & 0 & 1 \\
\hline Number of children & 3.099 & 1.437 & 1 & 17 \\
\hline Household size & 0.123 & 0.328 & 0 & 1 \\
\hline$N=149,951$ & & & & \\
\hline
\end{tabular}

